\title{
Animal reflections
}

\section{Marc Bekoff}

$\mathrm{R}$ esearchers are interested in animal awareness because they are curious to discover what animals might know about themselves. There are, however, longheld and polarized views about the degree of self-awareness in animals. Some people believe that only great apes have 'rich' notions of self - knowing who they are and/or having a 'theory of mind', which means being able to infer the states of minds of others whereas others argue that it is methodologically too difficult to address this question because animal (like human) minds are subjective and private. Many in this latter category do not attribute any sense of self to animals other than humans, and some, dismissing behavioural and neurobiological research on animal cognition, wonder whether animals are conscious of anything at all.

What might animals know about themselves? Most studies of animal self-awareness have been narrowly paradigm-driven. The 'red spot' technique was first used by Gordon Gallup to study animal self-awareness in chimpanzees; it and variations have been used on great apes and monkeys, as well as on a few dolphins and elephants. For primates, a spot is placed on the forehead of an anaesthetized individual and self-directed movements towards the spot are scored after he or she awakens and catches sight of themselves in a mirror, a high score indicating the presence of some degree of self-awareness. But in some cases, the data are derived from tests on small numbers of individuals, many of whom fail it because they do not make self-directed movements towards the spot. Those who pass the test might not be representative of wild relatives because they have had extensive

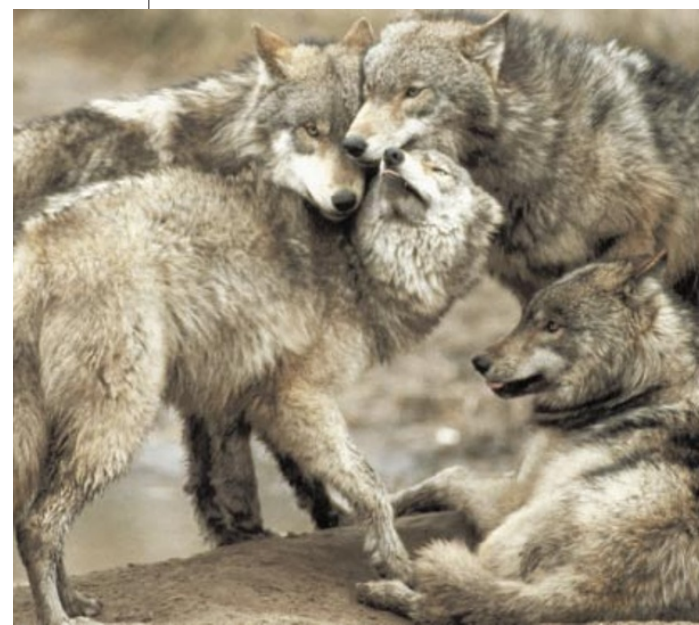

Social work: is the pack behaviour of grey wolves indicative of some degree of self-awareness? human contact and previous experience with mirrors, factors that might influence their trainability and willingness to use a mirror. Those who fail the test might show some sense of 'self' in other contexts, and other individual differences might also play a role.

Laboratory experiments can overlook the fact that many animals have evolved in complex webs characterized by variable social, sensory and other environmental features. A single technique based solely on visual cues is not the only valid test of self-awareness because many animals regularly use sensory modalities other than vision, either singly or together. Most wild animals do not know what they look like - although birds can acquire information about their plumage colour from reflections in drinking water - but they seem to know what they sound or smell like. Many birds distinguish their own from others' songs and numerous mammals discriminate their own from others' scents. Some rodents use odour to distinguish 'self' from 'other'; they preferentially associate or play with those who smell like them, or shun individuals who smell like them to avoid inbreeding.

Discriminating between 'own' and 'other' is not necessarily an indication of selfawareness, but in most cases we don't know if it is or isn't. Although no one has suggested that birds or rodents are self-aware to the degree that chimpanzees might be, we do not know precisely what these animals know about themselves. We must be careful neither to imbue animals with unknown cognitive capacities nor to rob them of skills that they might possess.

Researchers often dismiss non-primates when they investigate self-awareness. Social carnivores, such as grey wolves, who live in closely knit, orderly and efficient packs, could turn out to have well-developed self-awareness. Wolves engage in coordinated hunts and rear their young communally. Analyses of the behaviour patterns of individual wolves during these (and other) activities show that they have at least some awareness of what they are doing, what others are doing, and where each is located spatially. Similar observations have been compiled for other species.

Comparative data suggest that if we rely solely on mirror studies, we have been looking for self in the wrong places and on the wrong faces. The evidence also indicates that no other animal has the same degree of self as that possessed by most humans (an 'I-ness' or 'I-self', perhaps mediated by language). On the basis of traditional measures, many animals appear to have a sense of 'body-ness' or 'mine-ness', but not a sense of 'I-ness.'

Answers to challenging questions about self-awareness have wide-ranging conse-
Awareness

On traditional measures, many

animals appear to have a sense

of 'body-ness' or 'mine-ness',

but no sense of 'I-ness'.

quences because they are often used by researchers and lawyers as a litmus test for defending the sorts of treatments to which animals can be ethically subjected. However, it is not clear that self-awareness or other cognitive capacities should be used for such decisions. Some argue that a sense of 'I-ness' is morally relevant and necessary for experiencing pain. But even if an animal does not know 'who' she is, this does not mean she cannot feel that 'something painful is happening to this body'. Even though the experience of pain might not be the same across species, individuals of different species can still suffer their own type or version of pain. Self-awareness is not a reliable test for an objective assessment of well-being.

The concept of animal self-awareness remains open to different interpretations, but we will probably learn more about the mysteries of 'self' and 'body-ness' by using non-invasive neuroimaging techniques in combination with cognitive ethological studies. If we look at 'self-awareness' as 'bodyawareness', we might also discover more about how animals think and the perceptual and neurobiological processes underlying various cognitive capacities. Darwin's ideas about evolutionary continuity, together with empirical data ('science sense') and common sense, caution against the unyielding claim that humans - and perhaps other great apes and cetaceans - are the only species in which some sense of self has evolved.

Marc Bekoff is in the Department of Environmental, Population, and Organismic Biology, University of Colorado, Boulder, Colorado 80309-0334, USA.

\section{FURTHER READING}

Bekoff, M. Minding Animals: Awareness, Emotions, and Heart (Oxford Univ. Press, New York \& London, 2002).

Bekoff, M., Allen, C. \& Burghardt, G. M. (eds)

The Cognitive Animal: Empirical and Theoretical Perspectives on Animal Cognition (MIT Press, Cambridge, Massachusetts, 2002); see especially essays on self-awareness by Gallup, G. G., Anderson, J. R. \& Shillito, D. J.; Mitchell, R. W.; Shumaker, R. W. \& Swartz, K. B.

Mitchell, R. W. in Handbook of Self and Identity (eds Leary, M. R. \& Tangney, J.) 567-593 (Guilford, New York, 2002).

Reiss, D. Nature 418, 369-370 (2002).

Rilling, J. K. et al. Neuron 35, 395-405 (2002).

Rilling, J. et al. Am. J. Phys. Anthropol. Suppl. 30, 263 (2000).

Rilling, K. et al. Biol. Psychiat. 49, 146-157 (2001). 